\title{
Development of a field test for the detection of illegal bear products
}

\author{
Lindsay Peppin ${ }^{1, *}$, Ross McEwing ${ }^{2}$, Simon Webster ${ }^{3}$, Adrian Rogers ${ }^{4}$, \\ Denise Nicholls ${ }^{4}$, Rob Ogden ${ }^{2}$
}

\author{
${ }^{1}$ Molecular Ecology and Fisheries Genetics Laboratory, School of Biological Sciences, Environment Centre Wales, \\ Bangor University, Bangor, Gwynedd LL57 2UW, UK \\ ${ }^{2}$ Wildlife DNA Services, Tepnel RPS, Appleton Place, Appleton Parkway, Livingston, West Lothian EH54 7EZ, UK \\ ${ }^{3}$ School of Biological Sciences, Brambell Building, Bangor University, Bangor, Gwynedd LL57 2UW, UK \\ ${ }^{4}$ Tepnel Research Products and Services, 1 Newtech Square, Deeside Industrial Park, Deeside, Flintshire CH5 2NT, UK
}

\begin{abstract}
International trade in parts and derivatives is a recognised threat to the long term survival of the Asiatic black bear Ursus thibetanus and is therefore prohibited under the Convention on International Trade in Endangered Species of Wild Flora and Fauna (CITES). However, significant levels of illegal trade continue to be reported. Attempts to prevent illegal trade in bear parts are hampered by difficulties associated with the accurate identification of such items. In response, we have developed a qualitative lateral flow immunoassay (LFIA) dipstick for bear serum albumin detection. The visual detection limit was $10 \mathrm{ppm}$ of bear serum with a reaction time of $5 \mathrm{~min}$. The LFIA was validated on serum, blood, skin and liquid bile, and was able to detect bear albumin in all these sample types. Items confiscated during enforcement activities were also tested and the results confirmed by DNA sequence analysis. The LFIA accurately identified genuine bear bile crystals and bear bile capsules, although it was unable to consistently identify bear bone and some of the more complex traditional Asian medicines (TAM). The test can be performed by persons with little or no scientific training and may provide a novel method for customs and law enforcement officials to screen purported bear bile samples and gallbladders.
\end{abstract}

KEY WORDS: Ursus thibetanus $\cdot$ Illegal trade $\cdot$ Bile $\cdot$ Field test $\cdot$ Lateral flow immunoassay $\cdot$ LFIA

\section{INTRODUCTION}

Illegal trade in wildlife and wildlife products presents a serious threat to the long-term survival of certain species. One such species is the Asiatic black bear Ursus thibetanus, which is targeted to supply the global demand for bear bile. Bear bile has been a prized ingredient in traditional Asian medicine (TAM) for thousands of years, and was traditionally obtained by the hunting of wild bears, primarily $U$. thibetanus, for their gallbladders. However, declining bear populations led to the introduction of bile 'farms' in the 1980s, where bile is extracted from live, captive animals. The bile is dried and sold as crystals, or processed further into an array of medicinal and non-medicinal products. A single farm bear has an average productive life span of $5 \mathrm{yr}$, during which it will produce bile equivalent to 220 wild bears (Mills et al. 1995). This commercialisation of bile production generates more bile per annum than is consumed medicinally within Asia, which, coupled with the demand for TAM from expatriate populations, has led to the export of bile products and whole gallbladders out of Asian countries (Zhiyong 1999). The exported gallbladders come from both farmed and wild bears, which continue to be hunted to supply the demand for 'wild' gall (Phillips \& Wilson 2002), which is considered to be of superior quality to that of farmed bears. Indeed, there has been no documented conservation benefit of bear farms to wild populations (Mills et al. 1995, Maas 2000). 
Despite all bear species being listed within the Appendices of the Convention on International Trade in Endangered Species of Wild Flora and Fauna (CITES), significant international trade in bear parts and derivatives has been reported (e.g. Phillips \& Wilson 2002). Surveys conducted by the World Society for the Protection of Animals (WSPA) of traditional medicine stores in the USA, Canada, Taiwan, Japan, Singapore, Korea, Australia and New Zealand found bear products offered for sale in all countries. Many products were clearly labelled as having been manufactured in China and even named the bear farm of origin (Groves \& Eastham 2007). This illegal trade is recognised as a 'major threat' to the long-term survival of Ursus thibetanus (IUCN 2007). Furthermore, there is evidence that non-Asian bear species are being targeted to supply the demand for whole gallbladders (e.g. Anderson 1999, Twiss \& Thomas 1999).

Attempts to prevent illegal trade in bear parts and derivatives are hampered by difficulties associated with the accurate identification of such items. Bile products may be transported or sold unlabelled to avoid detection (Peppin et al. 2008) and bear gallbladders are morphologically indistinct from those of pigs or cows, which are fraudulently sold as bear (Mills \& Servheen 1994). These 'fake' items can only be distinguished from genuine bear parts by laboratory-based analyses, such as highperformance liquid chromatography (HPLC), thin layer chromatography (TLC) (Espinoza et al. 1993, Lin et al. 1997, Lin et al. 2000), Fourier transform infrared spectroscopy (FT-IR) analysis (Lin et al. 1997) and nuclear magnetic resonance (NMR) (Theis et al. 1988). However, these are costly, laboratory-based methods, requiring expensive equipment operated by highly trained personnel, and financially constrained law enforcement agencies rarely have the funds to pay for such testing.

Here, we report the development of a sensitive lateral flow immunoassay (LFIA) dipstick for the detection of bear (Ursidae) serum albumin. In recent years LFIAs have become a popular diagnostic tool due to their cost effectiveness, sensitivity, specificity and user-friendly analysis. After introducing the sample, no further handling steps are required, so even people with little or no training can perform the test effectively. Albumin is the most abundant plasma protein in mammals, constituting $60 \%$ of total plasma protein (Motrescu et al. 2006). Albumin is also present in mammalian bile (LaRusso 1984, Coleman 1987), although the exact concentration can vary within and between species (e.g. human bile 155 to $1485 \mu \mathrm{g} \mathrm{ml}^{-1}$, Delacroix et al. 1982). A LFIA able to detect bear albumin could potentially identify a wide range of bear parts and bile products and, as LFIAs are quick (generally <15 min) and simple to use by people with little or no scientific training, the test could be used by law enforcement officials working in the field.

\section{MATERIALS AND METHODS}

Preparation of the LIFA. Serum samples from 7 bear species (Ursus americanus, U. arctos, U. maritimus, U. ursinus, U. thibetanus, Tremarctos ornatus and Helarctos malayanus) were obtained (see 'Acknowledgements') and albumin extracted by ammonium sulphate precipitation. Polyclonal goat anti-bear antibodies were raised to a cocktail of albumins from these 7 species at Harlan Sera-Lab (Loughborough, UK), then purified by either Protein A affinity chromatography or bear albumin affinity chromatography. The Protein A purified antibodies were conjugated to blue latex particles (Polymer Laboratory); the latex particles were washed first with distilled water and then with $10 \mathrm{mM}$ sodium acetate buffer (NaAc, pH 5.5). The pellet was resuspended in $10 \mathrm{mM} \mathrm{NaAc}$ containing the antibodies at $200 \mu \mathrm{g} \mathrm{ml}^{-1}$, and the suspension mixed for $2 \mathrm{~h}$ at room temperature. Sea Block ${ }^{\mathrm{TM}}$ (EastCoast Bio) diluted 1:10 with $10 \mathrm{mM} \mathrm{NaAc}$ was added and the suspension mixed at room temperature for a further $30 \mathrm{~min}$. The antibody-latex suspension was washed twice in $10 \mathrm{mM}$ di-sodium tetraborate (DTB, pH 8.5) and then applied by an automatic airbrush system (Bio-Dot) onto a conjugate pad (glass fibre material) and dried at $36^{\circ} \mathrm{C}$ for $1 \mathrm{~h}$.

The bear albumin affinity-purified (unlabelled) antibodies (3 $\mathrm{mg} \mathrm{ml}^{-1}$ ) and Goldline 2 reagent (Tepnel BioSystems) were applied as 2 separate lines onto a nitrocellulose membrane (PRIMA ${ }^{\mathrm{TM}}$ 125, Whatman ${ }^{\circledR}$ ), also by the airbrush system, to form the test line and control line respectively. The membrane was dried for $1 \mathrm{~h}$ at $36^{\circ} \mathrm{C}$, then blocked with $0.9 \%$ phosphate buffered saline (PBS) containing $0.2 \%$ polyvinyl alcohol (PVA). The membrane was washed twice with distilled water, and dried for $1 \mathrm{~h}$ at $36^{\circ} \mathrm{C}$. The test strips were assembled together (sample transfer pad, conjugate pad, membrane, absorbent wick) on a clear plastic backing as shown in Fig. 1, cut into $5 \mathrm{~mm}$ strips using an automatic cutter, inserted into plastic dipstick cassettes and stored at $4^{\circ} \mathrm{C}$ in sealed pouches containing desiccant.

Test procedure and principle. The samples to be tested were hand-shaken in $2 \mathrm{ml}$ of extraction buffer (1:1 $0.9 \%$ saline/100 mM DTB) for $1 \mathrm{~min}$. The dipstick was then held in the extraction buffer for $2 \mathrm{~s}$ and laid on a flat surface to allow the sample to migrate along the test strip. The sample entered the test strip via the sample transfer pad and wetted through to the conjugate pad, where it mobilised the labelled antibodies (Fig. 1). Any bear albumin (analyte) present in the sample bound to the labelled antibodies. The sample then flowed along the nitrocellulose membrane, drawn by the absorbent wick. As the sample passed over the test line the analyte-detector complexes bound to the immobilised antibodies, producing a visible blue line 

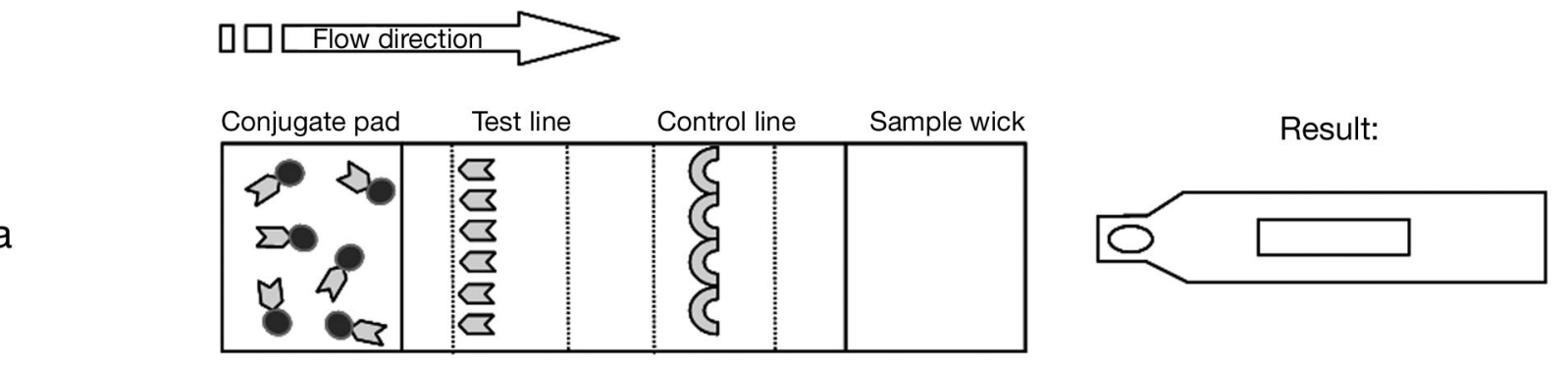

b
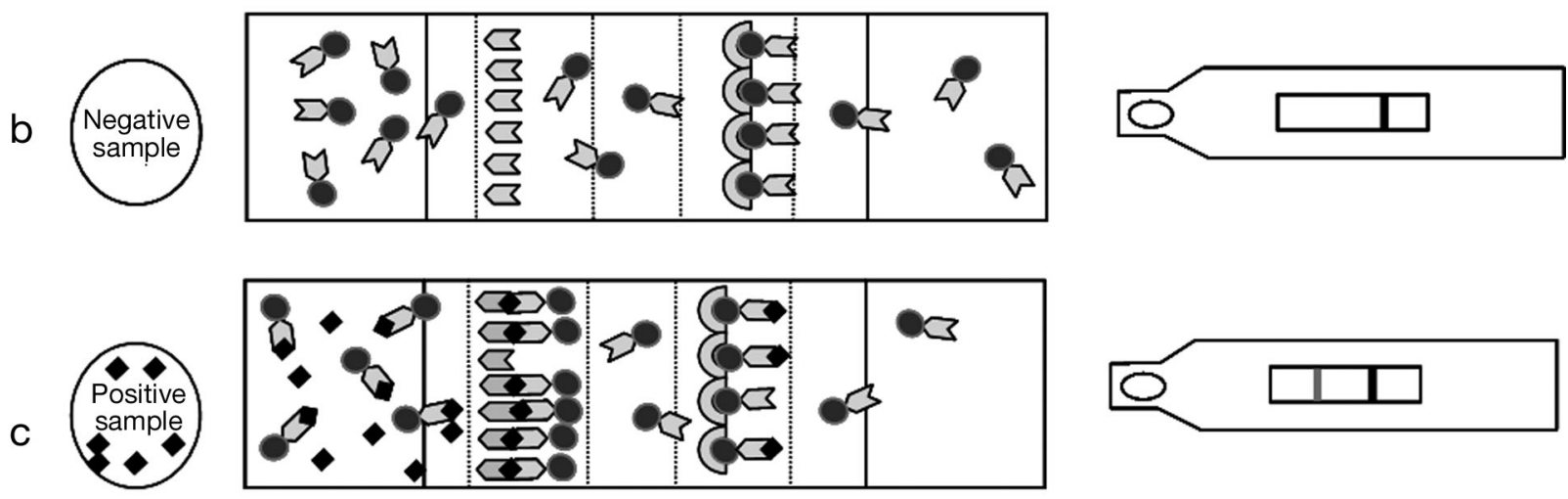

at the test line position. Any excess detector reagent was trapped by the control line (Fig. 1c). When a sample devoid of bear albumin was introduced to the LFIA, the labelled antibodies were still mobilised and flowed along the test strip, but no analyte-detector complex formed. No line appeared at the test position, but detector reagent was still trapped by the control line (Fig. 1b).

The test strips are assessed by eye after 5 min and graded as either 'positive' (blue lines visible at the test line and control line positions), 'negative' (blue line present at the control line position only) or 'invalid' (no lines at either position).

Cross-reactivity testing. The antibodies were tested for cross-reactivity against a range of mammalian and avian serum albumins (Sigma-Aldrich) diluted in extraction buffer. Cross-reactivity was defined as the appearance of a line (of any intensity) at the test line position within 5 min when albumin from a non-bear species was being tested. If cross-reactivity was detected, the goat anti-bear antibodies were passed over a chromatography column containing the albumin of the cross-reacting species bound to $\mathrm{CNBr}$-activated sepharose 4B (Amersham Pharmacia), thus removing the cross-reacting components of the polyclonal antibody mix by affinity chromatography. New test strips were made with the purified antibody and cross-reactivity testing was repeated.

Sensitivity testing. The sensitivity of the test strip was determined using serial dilutions of a bear serum 'cocktail' (equal parts Ursus americanus, U. arctos, U. maritimus, $U$. ursinus, $U$. thibetanus, T. ornatus and $H$. malayanus), U. maritimus blood and liquid bile (confirmed as 'bear bile' by HPLC analysis but species origin unknown). The range of concentrations tested was 0.1 to $100000 \mathrm{ppm}$.

Sample testing. Samples suspected to be bear parts or derivatives, confiscated during law enforcement activities, were tested using the LFIA. A dried gallbladder, a femur bone, 2 bottles of tablets named 'Fargelin for Piles' (one of which listed Fel Ursi-the pharmaceutical name for bear bile-as an ingredient), laryngitis pills and capsules labelled 'Capsulae Bearbile' were tested by the Metropolitan Police Wildlife Crime Unit (WCU) in London, UK. The femur bone was tested twice; first using dried material from the surface of the bone and second, using small slivers of bone material. All other items were tested once. 
The results, along with the extraction buffers containing the tested samples, were sent to our laboratory for genetic analysis. The 'Fargelin for Piles,' laryngitis pills and Capsulae Bearbile were also sent to our laboratory for testing with the LFIA in-house to assess whether consistent results were obtained in the laboratory and in the field.

Another dried gallbladder, 3 skin samples, and 5 sets of bile crystals suspected to be bear parts and derivatives were provided by WSPA and tested with the LFIA in-house. Bile samples from pig and sheep were also tested. Genetic analyses were performed to determine the species origin of all test samples.

Genetic analysis. In order to confirm the results of the LFIA, portions of the mitochondrial gene cytochrome $b$ were amplified using universal primers (Verma \& Singh 2003) and primers designed on Ursus thibetanus sequences (Peppin et al. 2008). These fragments were then sequenced and compared to published sequences to determine the species of origin. The universal primers can be used to amplify DNA from a wide range of animal species (including mammals, birds and reptiles), and are a valuable tool for identifying samples of unknown species origin. However, when DNA from more than one species is present in a sample (e.g. due to contamination, or the combining of more than one animal product in a TCM), mixed sequences can be generated that are impossible to identify. As some of the samples tested are TCMs containing a number of ingredients and furthermore are likely to be contaminated (e.g. with human DNA, due to handling during manufacture and sample testing), the extracted DNA was also amplified using the primers designed on $U$. thibetanus sequences (henceforth called UT primers). Although these primers have been demonstrated to amplify bear species other than $U$. thibetanus, they do not amplify human DNA, or DNA from species whose parts are often fraudulently sold as bear (e.g. pig and cow), making it possible to identify bear DNA even in mixed or contaminated samples.

DNA was extracted from the skin samples using an Invitrogen $^{\mathrm{TM}}$ PureLink $^{\mathrm{TM}}$ Genomic DNA Mini Kit (Invitrogen) following the manufacturer's protocol. DNA was extracted from the bile crystals and dried gallbladders following a different protocol given the high levels of PCR inhibitors (i.e. bile salts) present in these samples. Bile crystal samples were powdered using a Qiagen TissueLyser, and gallbladder samples were finely chopped. DNA was extracted from $200 \mathrm{mg}$ of the powders/chopped material using a QIAamp Stool Mini Kit (Qiagen) following the manufacturer's protocol with the following modifications: samples were initially dissolved in $1.6 \mathrm{ml}$ buffer ASL by incubation on a thermal mixer (Eppendorf AG thermomixer comfort) at $55^{\circ} \mathrm{C}$, placed on ice for 15 min after the addition of ethanol, and washed twice in buffer AW2. DNA was eluted from the column in $50 \mu \mathrm{l}$ of elution buffer. Total DNA extracted from the test samples was quantified by absorbance using a NanoDrop ${ }^{\circledR}$ ND1000 spectrophotometer (Nanodrop Technologies). Extraction controls were run in parallel to all extractions.

The PCR reaction mixtures (total volume $20 \mu$ ) contained $2 \mu \mathrm{l}$ of template DNA, 0.36 units ABgene Thermo-Start ${ }^{\circledR}$ DNA Polymerase, $1.1 \mathrm{mM} \mathrm{MgCl}_{2}$, $0.72 \times$ reaction buffer and $20 \mathrm{pmol}$ of each primer. The universal primers were mcb398 (TACCATGAGGACAAATATCATTCTG) and mcb869 (CCTCCTAGTTTGTTAGGGATTGATCG) (Verma \& Singh 2003). The UT primers were ut172f (GACGCGACTACAGCCTTTTC) and ut367r (CTATGAATGCGGTGGCTATAAC) (Peppin et al. 2008). Separate PCRs were set up for each primer pair (i.e. not nested PCR). Amplifications were carried out using a PTC-200 MJ Research thermocycler with the following conditions: an initial denaturation at $96^{\circ} \mathrm{C}$ for $15 \mathrm{~min}$, followed by 37 cycles of denaturation at $95^{\circ} \mathrm{C}$ for $45 \mathrm{~s}$, annealing at $60^{\circ} \mathrm{C}$ for $1 \mathrm{~min}$ and extension at $72^{\circ} \mathrm{C}$ for $1 \mathrm{~min}$; followed by a final extension step at $72^{\circ} \mathrm{C}$ for $5 \mathrm{~min}$. Amplification products were visualised under UV using ethidium bromide stained agarose gels.

Sequencing of PCR products. Amplified products were cleaned using exonuclease I and shrimp alkaline phosphatase following Werle et al. (1994). Cycle sequencing of cleaned products was performed using Applied Biosystems BigDye version 1.1 chemistries using both the forward and reverse primers, and sequencing products were resolved on an Applied Biosystems ABI 3730xl. Sequences were examined using Chromas 2.31 (Technelysium) and a consensus sequence generated from the forward and reverse sequences using Geneious ver. 2.5.4 software (Biomatters). Consensus sequences were compared with sequences deposited in GenBank using a BLASTn search (Altschul et al. 1990).

\section{RESULTS AND DISCUSSION}

\section{Cross-reactivity}

Initial testing indicated cross-reactivity with cow, pig, deer, sheep, cat and dog serum albumin. This crossreactivity was successfully removed by affinity chromatography purification against albumin from these species. After purification the LFIA was still able to detect albumin from all species of bear tested within $5 \mathrm{~min}$, yet gave a negative result for all other mammalian, avian and crustacean albumins tested (Table 1). 
Table 1. Results of cross-reactivity and sensitivity testing. Test strips were graded after 5 min as either positive (+) or negative (-)

\begin{tabular}{|c|c|c|c|c|c|c|c|}
\hline \multirow{2}{*}{ Sample type/species } & \multicolumn{6}{|c|}{ Concentration of test analyte (ppm) } & \multirow[b]{2}{*}{0.1} \\
\hline & 100000 & 10000 & 1000 & 100 & 10 & 1 & \\
\hline \multicolumn{8}{|l|}{ Albumin } \\
\hline Asiatic black bear Ursus thibetanus & - & + & + & + & + & - & - \\
\hline American black bear $U$. americanus & - & + & + & + & + & - & - \\
\hline Brown bear $U$. arctos & - & + & + & + & + & - & - \\
\hline Polar bear $U$. maritimus & - & + & + & + & + & - & - \\
\hline Sun bear Helarctos malayanus & - & + & + & + & + & - & - \\
\hline Sloth bear Melursus ursinus & - & + & + & + & + & - & - \\
\hline Spectacled bear Tremarctos ornatus & - & + & + & + & + & - & - \\
\hline Bear albumin cocktail & - & + & + & + & + & - & - \\
\hline Cow Bos taurus & - & - & - & - & - & - & - \\
\hline Pig Sus scrofa & - & - & - & - & - & - & - \\
\hline Sheep Ovis aries & - & - & - & - & - & - & - \\
\hline Buffalo Syncerus caffer & - & - & - & - & - & - & - \\
\hline Donkey Equus asinus & - & - & - & - & - & - & - \\
\hline Dog Canis familiaris & - & - & - & - & - & - & - \\
\hline Chicken Gallus domesticus & - & - & - & - & - & - & - \\
\hline Cat Felis silvestris catus & - & - & - & - & - & - & - \\
\hline Rabbit Oryctolagus cuniculus & - & - & - & - & - & - & - \\
\hline Mouse Mus musculus & - & - & - & - & - & - & - \\
\hline Goose Anser anser & - & - & - & - & - & - & - \\
\hline Pigeon Columba livia domestica & - & - & - & - & - & - & - \\
\hline Duck Anas platrhynches & - & - & - & - & - & - & - \\
\hline Kangaroo Macropus sp. & - & - & - & - & - & - & - \\
\hline Prawn Pandalus borealis & - & - & - & - & - & - & - \\
\hline Red deer Cervus elaphus & - & - & - & - & - & - & - \\
\hline \multicolumn{8}{|l|}{ Blood } \\
\hline U. americanus & - & + & + & + & + & - & - \\
\hline U. maritimus & - & + & + & + & + & - & - \\
\hline \multicolumn{8}{|l|}{ Bile } \\
\hline Bear bile $^{a}$ & - & + & + & + & - & - & - \\
\hline
\end{tabular}

\section{Sensitivity}

The LFIA detected bear serum and blood in the range 10 to $10000 \mathrm{ppm}$, but was less sensitive to liquid bile (Table 1). This could be due to albumin being present in lower quantities in bile than in serum and blood, or a component of the bile affecting the binding efficiency of the antibody/latex complexes at the test line. The test lines produced by the bile samples were much fainter than those produced by the albumin or blood samples, suggesting that there may be a component of the bile that interferes with test function (matrix effect, Selby 1999). The amount of bile tested must therefore be carefully measured to ensure a false negative is not produced. Indeed, false negatives were observed at concentrations above 10000 ppm of serum, blood and bile (Table 1). This is due to the high dose 'hook effect,' whereby the analyte concentration begins to block the interaction between the immobilised capture antibody and the analyte/labelled antibody complex (Miles et al. 1974, Rodbard et al. 1978). This is a well-documented phenomenon affecting immunoassays, which again em- phasises the need to use appropriate sample sizes/ dilutions (Selby 1999). No 'invalid' results were observed during testing.

\section{Sample testing}

The results of the LFIA and genetic analyses for the test samples are detailed in Table 2. The quantity of DNA recovered from the test samples ranged from

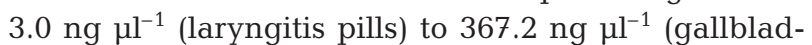
der). No DNA was detected in the extraction controls.

The 'Fargelin for Piles,' laryngitis pills and Capsulae Bearbile were tested with the LFIA in-house, and by personnel at the WCU who had not received any specific training on how to use the kits. The LFIAs gave the same results for each sample, regardless of who performed the test, indicating that they can be used accurately without specialist training.

The 2 whole gallbladders tested negative with the LFIA and were subsequently identified as gallbladders from domestic pigs by genetic analysis. Similarly, the pig and lamb bile tested negative. The skin, bile crys- 
Table 2. Results of lateral flow immunoassay (LFIA)/genetic analysis of test samples. The LFIA was graded as either positive $(+)$ or negative $(-)$. The genetic result gives the highest match returned by BLASTn search in the GenBank database. (*) Samples tested with the LFIA by staff at the Metropolitan Police Wildlife Crime Unit, London. The remaining samples were provided by WSPA and tested with the LFIA in-house. n/a: no DNA was amplified

\begin{tabular}{|c|c|c|c|}
\hline Sample & $\begin{array}{l}\text { LFIA } \\
\text { result }\end{array}$ & $\begin{array}{l}\text { Genetic analysis - BLA } \\
\text { Universal primers }\end{array}$ & $\begin{array}{l}\text { AST search result } \\
\text { UT primers }\end{array}$ \\
\hline Whole Dried Gallbladder & - & Sus scrofa & $\mathrm{n} / \mathrm{a}$ \\
\hline${ }^{*}$ Whole Dried Gallbladder & - & Sus scrofa & $\mathrm{n} / \mathrm{a}$ \\
\hline Skin & + & Ursus maritimus & U. maritimus \\
\hline Skin & + & U. americanus & U. americanus \\
\hline Skin & + & U. americanus & U. americanus \\
\hline Bile Crystals & + & U. thibetanus & U. thibetanus \\
\hline Bile Crystals & + & U. thibetanus & U. thibetanus \\
\hline Bile Crystals & + & U.thibetanus & U. thibetanus \\
\hline Bile Crystals & + & U. thibetanus & U. thibetanus \\
\hline Bile Crystals & + & U. thibetanus & U. thibetanus \\
\hline Pig Bile & - & Sus scrofa & $\mathrm{n} / \mathrm{a}$ \\
\hline Sheep Bile & - & Ovis aries & $\mathrm{n} / \mathrm{a}$ \\
\hline${ }^{*}$ Fargelin for Piles ${ }^{\mathrm{a}}$ & + & Mixed sequence & U. thibetanus \\
\hline *Fargelin for Piles & + & $\mathrm{n} / \mathrm{a}$ & $\mathrm{n} / \mathrm{a}$ \\
\hline${ }^{*}$ Laryngitis Pills & - & Mixed sequence & U. thibetanus \\
\hline${ }^{*}$ Capsulae Bearbile & + & U. thibetanus & U. thibetanus \\
\hline${ }^{*}$ Bone (femur) exterior & - & Helarctos malayanus & H. malayanus \\
\hline interior & + & H. malayanus & H. malayanus \\
\hline
\end{tabular}

degrade DNA (e.g. high temperatures). Although outside the scope of the present study, the development of such techniques would provide valuable tools for the detection of illegal bear and other wildlife products. An alternative explanation is that the LFIA result for this sample was a false positive, caused by a matrix effect or cross-reactivity with a species albumin not covered by our cross-reactivity analysis. As genetic testing of this sample was not possible, the analysis is viewed as 'inconclusive'.

The bone sample was tested twice by the WCU; dry material from the surface of the bone gave a negative result, whereas small slivers of bone material gave a positive result, albeit with a very faint test line. The extraction buffers containing the sample were tested with the LFIA again in our laboratory, and the same results were achieved, indicating the tests were performed correctly by the WCU and there was some other cause of the incongruent results. The genetic analysis identified the bone as Helarctos malayanus, confirming the positive LFIA result. Albumin is a constituent of the organic matrix of bone tissue, however it is possible that the extraction buffer used here is not efficient at releasing albumin from this sample type.

The laryngitis pills tested negative with the LFIA, yet Ursus thibetanus DNA was recovered during the genetic analysis (i.e. a false negative). One possible explanation is contamination in the lab, although this is unlikely, as no DNA was detected in the extraction and PCR controls. A more likely explanation is that any albumin present in the sample had degraded to the point where it could not be detected by the LFIA. DNA is physically more resistant to degradation than most proteins (Carracedo 2005), so it is feasible that DNA could persist in the sample even when most proteins could not. This indicates that certain bear products may be unsuitable for testing with the LFIA, due to the manufacturing process's destroying the target heatlabile protein.

\section{LFIA as a potential law enforcement tool}

When tested on a range of species albumins, the LFIA was shown to be specific to bear albumin. It successfully detected bear albumin in serum, blood, skin, liquid bile and bile crystal samples, indicating that it 
provides a useful tool for the identification of bear parts and derivatives. However since it would be unrealistic to test the LFIA on every species albumin, it is not possible to comment on whether or not the antibodies cross-react with untested species groups (e.g. fish, amphibians). Instead, the test has been validated against a defined set of likely substitute species. Furthermore, as bear bile is incorporated into many different products and medicines containing a massive diversity of components and the level of interference these additional ingredients may have on test function cannot be predicted, it is not possible to provide an exhaustive list of the items which are suitable for testing beyond those detailed in this paper. Another limitation of the LFIA is that it delivers a qualitative result ('positive' or 'negative') and further tests are required to determine the species of bear present in 'positive' samples. Definitive species identification is likely to be required within a legal framework, considering the differing levels of protection afforded to bear species/ populations under CITES.

Given these considerations the LFIA is intended to complement rather than replace current laboratory methods of analysis. For financially constrained enforcement agencies this system can offer a guide as to which products most warrant further investigation; the results presented here suggest that the LFIA can distinguish between genuine bear bile and that of domestic animals whose bile and gallbladders are fraudulently sold as bear. Lin et al. (1997) performed HPLC, HPTLC and FTIR analysis on 183 suspected bear products, and concluded that only 56 were genuine Ursus thibetanus derivatives; the rest were the bile and gallbladders of domestic animals (e.g. pig, goat). Given this high proportion of fraudulent items, a screening tool such as the LFIA would be very useful for determining which items to pursue with further laboratory analyses.

The identification of bear products is essential for reducing illegal trade in bear parts and derivatives, which is a major threat to the long-term survival of Ursus thibetanus. The installation of an effective identification system may help to reduce trade in $U$. thibetanus parts and derivatives and also prevent trade becoming a major threat to other bear species in the future.

Acknowledgements. We are grateful to the World Society for the Protection of Animals (WSPA) for funding this project, providing test samples and helping to co-ordinate sample collection. We also thank those parties that contributed samples to this project: Environment Canada (Ursus maritimus serum), the Zoological Society of London (U. ursinus serum), Woburn Safari Park (U. americanus serum), the Department of Conservation, New Zealand (Helarctos malayanus serum), and Le
Parc Zoologique de Paris (Zoo de Vincennes) (U. thibetanus, Tremarctos ornatus and $U$. arctos serum). We are also very grateful to D. Flint and the Metropolitan Police Wildlife Crime Unit for testing the kits and providing samples for testing and J. Coutts and the rest of the Tepnel team for their help and support during this project. This project was part funded by the Objective 1 - European Social Fund (ESF).

\section{LITERATURE CITED}

Altschul SF, Gish W, Miller W, Myers EW, Lipman DJ (1990) Basic local alignment search tool. J Mol Biol 215:403-410 Anderson GS (1999) Wildlife forensic entomology determining time of death in two illegally killed black bear cubs. J Forensic Sci 44:856-859

Carracedo A (2005) Forensic DNA typing protocols. Humana Press, Totowa, NJ

Coleman R (1987) Biochemistry of bile secretion. Biochem J 244:249-261

> Delacroix DL, Hodgson HJ, McPherson A, Dive C, Vaerman JP (1982) Selective transport of polymeric immunoglobulin A in bile. Quantitative relationships of monomeric and polymeric immunoglobulin $\mathrm{A}$, immunoglobulin $\mathrm{M}$, and other proteins in serum, bile, and saliva. J Clin Invest 70:230-241

- Espinoza EO, Shafer JA, Hagey LR (1993) International trade in bear gall bladders-forensic source inference. J Forensic Sci 38:1363-1371

Groves G, Eastham D (2007) From cage to consumer: the global trade in bear products from China to Asia and beyond. World Society for the Protection of Animals, London

IUCN (2007) 2007 IUCN Red List of threatened species. www.iucnredlist.org. Downloaded on 28 January 2008

LaRusso NF (1984) Proteins in bile: how they get there and what they do. Am J Physiol Gastrointest Liver Physiol 247:199-205

> Lin DL, Change HC, Chang CP, Chen CY (1997) Identification and differentiation of bear bile used in medicinal products in Taiwan. J Forensic Sci 42:817-823

Lin DL, Chang HC, Chen CY (2000) Identification and quantification of bile acids in bear bile by HPLC. J Food Drug Anal 8:283-288

Maas B (2000) The veterinary, behavioural and welfare implications of bear farming in Asia. World Society for the Protection of Animals, London

Miles LE, Lipschitz DA, Beiber CP, Cook JD (1974) Measurement of serum ferritin by a two-site immunoradiometric assay. Anal Biochem 61:209-224

Mills JA, Servheen C (1994) The Asian trade in bears and bear parts: impacts and conservation recommendations. Int Conf Bear Res Manag 9:161-167

Mills JA, Chan S, Ishihara A (1995) The bear facts: the East Asian market for bear gall bladder. TRAFFIC International, Cambridge, UK

Motrescu I, Oancea S, Rapa A, Airinei A (2006) Spectrophotometric analysis of the blood plasma for different mammals. Roman J Biophys 16:215-220

Peppin L, McEwing R, Carvalho GR, Ogden R (2008) A DNA based approach for the forensic identification of Asiatic black bear (Ursus thibetanus) in a traditional Asian medicine. J Forensic Sci (in press)

Phillips T, Wilson P (2002) The bear bile business: the global trade in bear products from China to Asia and beyond. World Society for the Protection of Animals, London

> Rodbard D, Feldman Y, Jaffe ML, Miles LE (1978) Kinetics of two-site immunoradiometric (sandwich) assays - II. Stud- 
ies on the nature of the 'high dose hook effect'. Immunochemistry 15:77-82

Selby C (1999) Interference in immunoassay. Ann Clin Biochem 36:704-721

Theis JH, de Ropp JS, Schwab RG, Banks J, Levine K (1988) Nuclear magnetic resonance to differentiate bear, pig and cow bile for forensic investigations. Wildl Soc Bull 16: 430-433

Twiss MP, Thomas VG (1999) Illegal harvests of black bears, sale of black bear parts, and the Canadian legislative

Editorial responsibility: Mike Bruford, Cardiff, UK response. Wildl Soc Bull 27:692-697

Verma SK, Singh L (2003) Novel universal primers establish identity of an enormous number of animal species for forensic application. Mol Ecol Notes 3:28-31

Werle E, Schneider C, Renner M, Volke M, Fiehn W (1994) Convenient single step, one tube purification of PCR products for direct sequencing. Nucleic Acids Res 22: $4354-4355$

Zhiyong F (1999) The development of bear farming in China. 3rd Int SympTrade in Bear Parts, Seoul

Submitted: April 10, 2008; Accepted: August 5, 2008

Proofs received from author(s): September 16, 2008 